\title{
Technological solutions for the cultivation of potatoes in the organic farming agroecosystem
}

\author{
D.A. Maksimov, V.B. Minin, A.N. Perekopskiy, and A.M. Zakharov \\ Federal State Budgetary Scientific Institution 'Federal Scientific Agroengineering Center VIM', \\ branch in Saint Petersburg, Filtrovskoje highway, 3 p.o. Tiarlevo, 196625 Saint Petersburg, Russia
}

\begin{abstract}
One of the main tasks of organic production of agricultural products is to reduce the load on agroecosystems while simultaneously obtaining a yield indicator of high consumer quality, as with intensive production technologies, and this can be attained only through the fuller use of the biological potential of a crop, species, variety. In the production of agricultural products using biologized machine technologies, they interact with the environment: the atmosphere, hydrosphere and soil. The research is aimed to the creation of adaptive biologized machine technologies that ensure the efficient use of natural resources in the production of agricultural products with a minimum impact on the environment. The research object is the potato agrocenosis in the crop rotation of tilled and field crops. The crop rotation includes potatoes, beets, perennial legumes and cereals. In the experiment, potatoes of the Udacha variety (superelite), zoned for the Leningrad region, were cultivated. Particular attention was paid to the assessment of possible environmental risks in the implementation of the selected technological solutions for growing potatoes, as well as the fight against weeds, since the use of synthetic herbicides, fungicides, insecticides, etc. radically contradicts GOST 33980 - 2016 "Organic products. Rules for production, processing, labeling and sale".
\end{abstract}

\section{Introduction}

In the context of the intensification of the crisis in the domestic economy and the growing tension in the political situation in the world, the problem of the country's food security is becoming more urgent. Russia's current high dependence on food imports poses an immediate threat to the country's sovereignty and requires vigorous measures to replace food imports with nationally produced products.

In this regard, recently, the accelerated import substitution of food has become one of the main directions of the state agrarian policy aimed at achieving food independence of the country [1].

One of the promising areas that can contribute to the development of import substitution in the Russian Federation is the simultaneous development of potentially competitive, environmentally friendly areas of agricultural production. One of these areas is the organic production of agricultural products, both animal husbandry and crop production, also including organic production of seeds, animal feed, and so on, to complete a complete production cycle and complete self-sufficiency of the country's population. [2-4]. 
The creation and implementation of machine technologies in agricultural production without proper monitoring and forecasting of the consequences of their impact on the environment in the long term cannot guarantee not only the country's food security, but also creates a threat of irreversible negative consequences.

The research is aimed to the creation of adaptive biologized machine technologies that ensure the efficient use of natural resources in the production of agricultural products with a minimum impact on the environment.

\section{Materials and methods}

The object of research is potato agrocenosis in organic crop rotation, where row crops and field crops are involved.

The organic crop rotation is six-field and includes fields:

1-potato variety "Udacha";

2-beetroot "Two-seeded TSKHA";

3 -coverless sowing of clover and timothy;

4-perennial grasses 1 year;

5 -perennial grasses 2 year;

6-perennial grasses 3 years with sowing, after plowing winter rye for green fertilization [5-7].

Work in the crop rotation of organic production continued (the beginning of the experience was laid in 2016). In the field season of 2020, an experiment was performed in which three groups of factors were studied in the framework of the use of biologized technology of potato cultivation:

- the level of mineral nutrition, due to the introduction of organic fertilizer BIAGUM, produced by IAEP-branch of FSBRI FNATS VIM;

- the effect of additional biological nitrogen provided by the introduced microorganisms - nitrogen fixers (Flavobacterin);

- the effect of biofungicides, biological plant protection products, the development of the FSBRI VIZR.

Since the principles of organic production provide for the restoration of natural soil fertility and the use of new innovative, nature-like technologies that do not damage the world around them, but exist in harmony with it and allow restoring the balance between the biosphere and technosphere disturbed by humans, key attention was paid to assessing possible environmental risks when applying the selected technological solutions in the crop rotation of organic production $[8,9]$.

In the experiment, potatoes of the Udacha variety (superelite), zoned for the Leningrad region, were cultivated, its predecessor was white mustard green manure. Organic fertilizer BIAGUM [10] was applied in two versions, 4.3 and $8.6 \mathrm{t} / \mathrm{ha}$ (if translated into nitrogen, then 80.0 and $160.0 \mathrm{~kg} / \mathrm{ha}$ ).

The experiment scheme is presented in Table 1.

Table 1. Scheme of options for planting potatoes

\begin{tabular}{|c|c|c|}
\hline Experiment No. & Amount of fertilizer & Biological product \\
\hline 1 & None & None \\
\hline 2 & None & Kartofin \\
\hline 3 & None & Flavobacterin \\
\hline 4 & $80.0 \mathrm{~kg}$ of nitrogen & None \\
\hline 5 & $80.0 \mathrm{~kg}$ of nitrogen & Kartofin \\
\hline 6 & $80.0 \mathrm{~kg}$ of nitrogen & Flavobacterin \\
\hline 7 & $80.0 \mathrm{~kg}$ nitrogen $+80.0 \mathrm{~kg}$ nitrogen in top dressing & Kartofin \\
\hline
\end{tabular}




\begin{tabular}{|c|c|c|}
\hline 8 & $80.0 \mathrm{~kg}$ nitrogen $+80.0 \mathrm{~kg}$ nitrogen in top dressing & Kartofin + Fitolar G \\
\hline 9 & $160.0 \mathrm{~kg}$ of nitrogen & Kartofin \\
\hline
\end{tabular}

In the experiment with potatoes, the biological preparation "Kartofin", developed by the specialists of the FSBRI VIZR, was used; it was created on the basis of the collection producer strain B. subtilis I-5 12/23, by spraying at a rate of $31 / \mathrm{ha}$. In one of the variants, a multifunctional multi-bioconversion microbiological preparation Fitolar ShV, G based on the collection producer strain T. asperellum T-36, developed at the FSBRI VIZR, was also used for introduction into the soil along with planting potatoes [11, 12].

In two variants of the experiment, a complex microbiological preparation with a nitrogenfixing function developed by VNIISKhMB, Flavobacterin, is used.

Two options were compared, one with plant protection with biological devices, and the other without protection with biological preparations (without organic fertilizer Biagum and with the introduction of organic fertilizer Biagum with a dosage of $80 \mathrm{~kg}$ of nitrogen per hectare) $[13,14]$.

Plot area $-5.6 \times 11=61.6 \mathrm{~m}^{2}$. The repetition rate was fourfold, the location of the plots was randomized.

On May 26, organic fertilizer Biagum was transported to the experimental landfill. The application of organic fertilizer and cutting of the ridges for planting potatoes with the simultaneous incorporation of fertilizer into the ridges was performed on the same day, these two technological operations were performed one after the other in order to prevent nitrogen from escaping into the atmosphere. The planting of potatoes with simultaneous treatment with the Kartofen preparation was performed by a two-row planter Lida - 201 on May 27, 2020, and on June 9, soil samples were taken from individual plots [15].

An analysis of the data obtained shows that the total potato yield in 2020 is slightly lower than in 2019, due to the prevailing weather conditions (slightly less warm May and increased precipitation in June - August.

\section{Results and discussion}

The yield of standard tubers in the experiment was obtained in the range from 18.47 to 31.77 $\mathrm{t} / \mathrm{ha}$, depending on the option, table 2 and figure 1.

Table 2. Yield of standard potato tubers of the Udacha variety and the share of small potatoes in the biological yield.

\begin{tabular}{|l|l|l|l|l|}
\hline $\begin{array}{l}\text { Experiment } \\
\text { No. }\end{array}$ & $\begin{array}{l}\text { Dose, } \\
\text { nitrogen } \\
\mathrm{kg} / \mathrm{ha}\end{array}$ & Biological product & Yield (t/ha) & $\begin{array}{l}\text { Share of } \\
\text { small potatoes } \\
\text { in, \% }\end{array}$ \\
\hline 1 & 0 & None & 20.25 & 2.07 \\
\hline 2 & 80 & None & 25.88 & 1.68 \\
\hline 3 & 0 & Flavobacterin & 22.87 & 1.36 \\
\hline 4 & 80 & Flavobacterin & 27.33 & 1.38 \\
\hline 5 & 0 & Kartofin & 18.47 & 2.4 \\
\hline 6 & 80 & Kartofin & 27.51 & 1.66 \\
\hline 7 & 80 & Kartofin + Fitolar, G & 28.20 & 1.84 \\
\hline 7 & 160 & Kartofin & 31.77 & 0.83 \\
\hline $\mathrm{HCP}_{05}$ & & 2.07 & \\
\hline
\end{tabular}

Without the use of compost and plant protection products, the yield was $20.25 \mathrm{t} / \mathrm{ha}$. The use of compost made it possible to raise it to $25.88 \mathrm{t} / \mathrm{ha}$, that is, by more than 5 tons.

Flavobacterin, which promotes both the development of soil nitrogen fixation and the enhancement of the general condition of potato plants, provided a significant increase in yield 
of $2.62 \mathrm{t} / \mathrm{ha}$ even without compost. The use of compost, together with Flavobacterin, increased the yield by another $4.46 \mathrm{t}$ to $27.33 \mathrm{t} / \mathrm{ha}$.

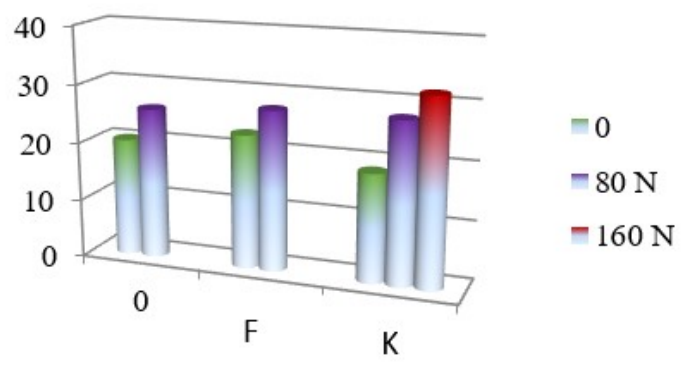

Fig. 1. Impact of biological products and fertilizers on yield.

The potato yield in the experiment with the biofungicide Kartofin, which was not provided with compost, did not differ significantly from the control variant.

The use of compost together with Kartofin gave a yield increase of $9.04 \mathrm{t} / \mathrm{ha}$, however, in the variant where Fitolar $G$ was additionally used, the increase was already $9.73 \mathrm{t} / \mathrm{ha}$.

The maximum yield of $31.77 \mathrm{t} / \mathrm{ha}$ was achieved with the introduction of an increased dose of compost (160 kg N/ha) together with Kartofin.

It should be noted that the lowest content of small potatoes was in the variants with Flavobacterin and in the variant with an increased dose of compost and Kartofin. This phenomenon is explained by the formation under these variants of the most favorable conditions for the full development of potato tubers.

The use of biological products Kartofin, SK and Fitolar G significantly reduced the development of fungal diseases on potato plants during the entire observation period. The biological efficiency for the development of a complex of fungal diseases ranged from 81.2 $-95.3 \%$ and only before mowing the tops decreased to $43.8-67.3 \%$.

It was found that biological products Kartofin, SK and Fitolar G had a positive effect on the infestation of tubers, reducing this indicator by $22-36 \%$ in comparison with the control.

The dry matter content in the tubers ranged from 18.82 to $22.34 \%$, table 3 . It should be noted that the lowest dry matter content was recorded in variants without the use of biological products. This indicates that biological products promoted more efficient vital activity of potato plants and better biosynthesis. As expected, a lower dry matter content is also observed in the variant with the maximum compost dose, here is also the maximum concentration of nitrates. The increased content of nitrates promoted the active accumulation of water.

Table 3. Content of dry matter and nitrates in potato tubers.

\begin{tabular}{|c|c|c|c|c|}
\hline $\begin{array}{c}\text { Experiment } \\
\text { No. }\end{array}$ & $\begin{array}{c}\text { Fertilizer quantity, kg } \\
\text { nitrogen/ha }\end{array}$ & $\begin{array}{c}\text { Biological } \\
\text { product }\end{array}$ & $\begin{array}{c}\text { Dry matter } \\
\text { content, \% }\end{array}$ & $\begin{array}{c}\text { Content of } \\
\text { nitrates, } \mathrm{mg} / \mathrm{kg}\end{array}$ \\
\hline 1 & 0 & None & 19.24 & 46 \\
\hline 2 & 80 & None & 19.80 & 61 \\
\hline 3 & 0 & Flavobacterin & 20.49 & 210 \\
\hline 4 & 80 & Flavobacterin & 21.40 & 178 \\
\hline 5 & 0 & Kartofin & 22.34 & 125 \\
\hline 6 & 80 & Kartofin & 20.05 & 169 \\
\hline 7 & 80 & $\begin{array}{c}\text { Kartofin }+ \\
\text { Fitolar, G }\end{array}$ & 20.72 & 119 \\
\hline 8 & 160 & Kartofin & 18.82 & 226 \\
\hline
\end{tabular}

Content of nitrates in potatoes of all options is lower than MAC. When using biological products, the content of nitrates in potato tubers increased, which reflects the increased 
mineralization activity of microflora in these variants of the experiment, and potato plants used this additional amount of nitrogen.

In the biologized technology used, gentle soil cultivation in the spring (cultivation and immediately cutting of ridges) was performed at the optimum time. A significant number of earthworms in the soil of the experiment during the growing season served as an indicator of the favorable soil conditions. Only biological pesticides were used, which also did not harm natural biodiversity.

The only environmental threat was the accumulation of nitrates in the soil during processing and composting.

The compost was applied to the soil on the twentieth of May, a few days before the potatoes were planted. With the first dose of compost, about $1.5 \mathrm{~g}$ of compost got into each kilogram of soil, and with it $1.5 \mathrm{mg}$ of mineral forms of nitrogen and about $4 \mathrm{mg}$ of total nitrogen. Table 4 shows the results of calculating the rate of accumulation of forms of mineral nitrogen in the soil of the experiment for the period from the end of May to 10 June.

Table 4. The impact of organic fertilization on the rate of accumulation of forms of mineral nitrogen in the soil, $\mathrm{kg}$ nitrogen/ha per day

\begin{tabular}{|c|c|c|}
\hline \multirow{2}{*}{ Fertilizer quantity, kg nitrogen/ha } & \multicolumn{2}{|c|}{ Year of research } \\
\cline { 2 - 3 } & 2019 & 2020 \\
\hline None & 2.42 & 1.48 \\
\hline 80 & 6.58 & 5.18 \\
\hline 160 & 9.20 & 9.38 \\
\hline
\end{tabular}

It should be noted that starting from the twenties of May, when the first soil samples were taken (before composting), the average daily temperature was above 10 degrees. This contributed to the development of soil microflora and the active development of the mineralization process. In the control variant, $1.48-2.42 \mathrm{~kg} / \mathrm{ha}$ forms of mineral nitrogen (predominantly nitrate) were mineralized and formed in the soil. The composting has significantly intensified this process. It should be noted that with a dose of compost, a relatively small amount of nitrogen-containing compounds (about $4 \mathrm{mg} / \mathrm{kg}$ of total nitrogen) was introduced into the soil, however, in variants with compost, $5.18 \mathrm{mg}$ of nitrate and ammonium nitrogen were formed daily in 2020 and $6.58 \mathrm{mg}$ - in 2019 . Thus, the compost activated the subsoil microflora and provided additional mineralization of soil nitrogen, significantly exceeding the nitrogen content in the compost itself.

Table 5 shows the results of the analysis of soil samples taken during the growing season of 2020 .

Table 5. Nitrates in soil, experiment in 2020

\begin{tabular}{|c|c|c|c|c|c|c|}
\hline $\begin{array}{l}\text { Fertilizer amount, } \\
\text { nitrogen/ha }\end{array}$ & Steel & 22.05 .20 & 9.06 .20 & 29.06 .20 & 21.07 .2020 & 25.10 .20 \\
\hline None & 0 & \multirow{8}{*}{$6 \underline{+3}$} & 29 & 283 & 12 & 83 \\
\hline 80 & 0 & & 165 & 398 & 27 & 138 \\
\hline None & Flavobacterin & & 75 & 205 & 6 & 72 \\
\hline 80 & Flavobacterin & & 211 & 334 & 40 & 116 \\
\hline None & Kartofin & & 75 & 288 & 12 & 90 \\
\hline 80 & Kartofin & & 152 & 368 & 11 & 111 \\
\hline 80 & $\begin{array}{l}\text { Kartofin }+ \\
\text { Fitolar }\end{array}$ & & 102 & 403 & 6 & 165 \\
\hline 160 & Kartofin & & 245 & 464 & 23 & 83 \\
\hline
\end{tabular}

Noteworthy is the high accumulation of nitrate nitrogen by the end of June in the control variant $(283 \mathrm{mg} / \mathrm{kg})$. This is due to the high content of organic matter in the soil $(8-10 \%)$, which provides such active mineralization and an increase in the content of nitrates, even 
without composting, but with regular treatments. As expected, both compost and biological products contributed to an even greater activation of mineralization and a further increase in the content of nitrates in the soil. However, these nitrate stocks are not particularly hazardous as they are the developing potato plants almost all and swallowed. By the twenty-first of July, no more than $40 \mathrm{mg}$ of nitrates per $\mathrm{kg}$ of soil remained in the soil, but the absorption of nitrogen continued.

Particular attention should be paid to the accumulation of significant amounts of nitrates and all mineral nitrogen in the autumn period (by the end of October). This phenomenon is associated, on the one hand, with active soil cultivation during the harvesting of potatoes, which contributed to the activation of mineralization processes, and on the other hand, with the established rather warm weather.

In the second experiment, a variety testing of potato varieties was performed (table 6).

Table 6. Yield indicator in the experiment on variety suitability for organic production conditions

\begin{tabular}{|c|c|c|}
\hline Cultivar & Yield (t/ha) & $\begin{array}{c}\text { Small-size fraction } \\
\text { share in, \% }\end{array}$ \\
\hline League & 15.47 & 3.63 \\
\hline Ryabinushka & 19.03 & 3.08 \\
\hline Nevsky & 22.50 & 1.50 \\
\hline Yelizaveta & 15.11 & 0.94 \\
\hline $\mathrm{HCP}_{0.95}$ & 1.486 & \\
\hline
\end{tabular}

Under rather harsh conditions (without using compost) the highest yield was shown by the variety Nevsky, the smallest Liga and Elizaveta. Apparently, varieties Liga and Ryabinushka could not realize their potential due to insufficient nutrient supply. This is evidenced by the increased share of small potatoes in the biological yield. Nevertheless, all four varieties have shown a fairly high productivity under test conditions.

Thus, pursuant to the 2020 research results, the efficiency of the developed version of the technology for the production of organic potatoes is confirmed. The combined use of compost at a dose of $4.3 \mathrm{t} / \mathrm{ha}$ and biological products made it possible to achieve the yield of standard tubers of $27.3-28.2 \mathrm{t} / \mathrm{ha}$ with their low incidence of fungal diseases. With an increase in the compost dose to $8.6 \mathrm{t} / \mathrm{ha}$, the yield increased to $31.77 \mathrm{t} / \mathrm{ha}$, but the dry matter content in the tubers decreased and the nitrate content increased, while biological products significantly activated the accumulation of mineral forms of nitrogen in the soil, which contributed to the enhancement of nitrogen nutrition of potato plants. Significant accumulation of nitrates in the soil in the autumn period was noted, which can pose a threat of nitrogen losses, primarily nitrates, as a result of leaching. Therefore, it is required to propose methods of planting winter stubble crops after harvesting row crops that will eliminate these threats.

\section{Conclusion}

Regularities of the formation of potato productivity from the prevailing weather and climatic conditions, the supply of nutrients and plant protection products, the selected cultivation methods were obtained. The combined use of organic fertilizer BIAGUM, produced in the department of engineering ecology of the IAEP branch of the FSBRI FNATS VIM and modern biological devices used for plant protection, which were developed by specialists of the FSBRI VIZR, has proven itself, which made it possible to obtain a good yield indicator for organic production, it amounted to 32 tons/ha of potatoes of high consumer quality. Herewith, it was confirmed that by applying current technological methods, technical means in organic production technologies, it is possible to obtain a yield close to the yield indicators of intensive technologies. Herewith, organic production of agricultural products, in contrast 
to intensive and high-intensity, can significantly reduce the load on agroecosystems, by eliminating the use of synthetic herbicides, fungicides, insecticides, synthetic growth regulators, etc., and maintaining a healthy state soil and an increase in its fertility and biological activity is achieved through the use of special crop rotations, including the cultivation of legumes and other green manure crops.

\section{References}

1. S. Hyun, S. M. Yang, J. Kim, K. S. Kim, J. H. Shin, S. M. Lee, B.-W. Lee, R. M. Beresford, D. H. Fleisher, Computers and Electronics in Agriculture, 181, № 105936 (2021)

2. O. Gorb, I. Yasnolob, T. Chayka, O. Zoria, T. Dugar, P. Shvedenko, O. Kalian, Y. Lypii, N. Protsiuk, Journal of Environmental Management and Tourism, 11, 1588 (2020)

3. A. P. Glinushkin, V. I. Startsev, L. V. Startseva, IOP Conference Series: Earth and Environmental Science, 459, 062069 (2020)

4. S. O. Bastaubayeva, R. K. Sagitov, International Journal of Pharmaceutical Research, 12, $2156(2020)$

5. H. S. Wulanningtyas, Y. Gong, P. Li, N. Sakagami, J. Nishiwaki, M. A. Komatsuzaki, Soil and Tillage Research, 205, 104749 (2021)

6. X. Hou, R. Li, Transactions of the Chinese Society for Agricultural Machinery, 51, 262 (2020)

7. C. A. Kwiatkowski, E. Harasim, Agronomy, 10, 1045 (2020)

8. I. M. Fomin, E. E. Oreshin, G. A. Loginov, A. M. Zakharov, In the collection book: Ecology and agricultural technologies: agro-engineering solutions. materials of the 7 th International Scientific and Practical Conference, 141 (2011)

9. G. A. Loginov, I. M. Fomin, E. E. Oreshin, A. M. Zakharov, Technologies and technical means of mechanized production of crop and livestock products, 82, 51 (2010)

10. V. B. Minin, V. D. Popov, D. A. Maksimov, A. A. Ustroev, S. P. Melnikov, E. Papushin, Agronomy Research, 18, 1359 (2020)

11. J. Jin, J. D. Wood, A. Franks, R. Armstrong, C.Tang, Soil Biology and Biochemistry, 144, $107780(2020)$

12. Yu. A. Titova, I. L. Krasnobayeva, Technologies and technical means of mechanized production of crop and livestock products, 2(99), 164 (2019)

13. N. V. Romanovsky, A.N. Perekopsky, Technologies and technical means of mechanized production of crop and livestock products, 98, 101 (2019)

14. A. N. Perekopsky, A. M. Zakharov, Journal of Advanced Research in Technical Science, 18, 61 (2020)

15. T. Gnatiuk, Biosystems Diversity, 26, 71 